Revista Electrónica Complutense de Investigación en Educación Musical ISSN-e: 1698-7454

http://dx.doi.org/10.5209/RECIEM.53915

\title{
Heinrich Neuhaus: intuición y método en la enseñanza del piano
}

\author{
Salve Márquez Sánchez; ; Alfonso Méndiz Noguero²
}

Recibido: 15 de octubre de 2016 / Aceptado: 22 de febrero de 2017

Resumen: Heinrich Neuhaus fue uno de los protagonistas en la creación y evolución de la escuela pianística soviética. Profesor del Conservatorio de Moscú desde 1922 hasta su muerte en 1964, sus particulares métodos de enseñanza atrajeron muy pronto la atención de músicos y pedagogos. El interés que suscitó su estilo docente hizo que se realizaran grabaciones de algunas de sus clases, dando así lugar a un valioso material en el que se incluyen registros estenográficos y grabaciones sonoras. En este trabajo se ha llevado a cabo un detallado análisis de estas fuentes junto al estudio de sus artículos, cartas y otros documentos personales — en su mayoría sin traducir y poco conocidos en Occidente-, para así profundizar en la comprensión del enfoque humanista de su método docente. También se exploran las prácticas que hicieron de Neuhaus un pedagogo de una influencia excepcional, y se ofrece un detallado análisis de sus sesiones de clase, incluyendo estrategias metodológicas y de organización.

Palabras clave: Heinrich Neuhaus; educación musical; método de enseñanza; enseñanza individualizada; escuela pianística soviética

\section{[en] Heinrich Neuhaus. Intuition and method merge in piano teaching}

\begin{abstract}
Heinrich Neuhaus was deeply involved in the creation and evolution of the Soviet piano school. He taught at the Moscow Conservatory from 1922 until his death in 1964 and his particular teaching methods soon attracted the attention of pedagogues and musicians, who enthusiastically attended his lessons. The interest his teaching style generated at that time led to the recording of some of his lessons, providing extensive material among which includes stenographic records and many sound recordings. These primary sources have been studied in this paper, along with his articles, letters, and other personal documents - mostly un-translated and little known in the West—, in order to provide a deeper understanding of his humanistic and comprehensive approach. This article explores those practices, which made Neuhaus an exceptionally influential pedagogue, and provides a detailed analysis of his class sessions, including organizational and methodological strategies.
\end{abstract}

Keywords: Heinrich Neuhaus; music education; teaching method; individualized teaching; Soviet piano school

Sumario. 1. Introducción: planteamiento del problema. 2. El estado de la cuestión. 3. Metodología. 4. Análisis de datos. 5. Conclusiones. 6. Referencias bibliográficas.

Cómo citar: Márquez Sánchez, S.; Méndiz Noguero, A. (2017). Heinrich Neuhaus: intuición y método en la enseñanza musical, en Revista Electrónica Complutense de Investigación en Educación Musical 14, 285-304.

\footnotetext{
1 Conservatorio Superior de Música de Málaga spmsanchez@gmail.com

2 Universidad Internacional de Cataluña amendiz@uic.es
} 


\section{Introducción: planteamiento del problema}

El nombre de Heinrich Gustavovich Neuhaus es ampliamente conocido en el ámbito de la enseñanza musical como autor de la obra El Arte del Piano. Lo cierto es que no fue un pedagogo en sentido estricto, como evidencia su célebre frase: "¡Odio la pedagogía! Pero amo a mis alumnos" (citado en Richter, 2007, p. 6). Sin una formación específica en Pedagogía, su poliédrico perfil humanista, unido a una dilatada trayectoria como profesor, hicieron de él una figura cumbre tanto en el ámbito de la interpretación pianística como en el de la enseñanza instrumental.

La sistematización de su herencia pedagógica no ha sido hasta el momento objeto de investigación profunda debido, principalmente, a barreras idiomáticas. Sin embargo, entendemos que esta supone una pieza clave para comprender el florecimiento de la escuela pianística rusa durante el siglo pasado. A su vez, supone una contribución importante para fundamentar la enseñanza del piano sobre sólidas bases científicas.

Apoyándonos en el método del caso, cada vez más frecuente en la investigación educativa (Álvarez y San Fabián, 2012), nos proponemos abordar las distintas facetas de su actividad docente y analizar sistemáticamente las metodologías que empleó en el aula. Para ello analizaremos un conjunto de fuentes primarias, algunas de recopilación reciente, entre las que destacan: 10 registros estenográficos de los años 1936-1939 y 1945, 6 grabaciones datadas entre 1954 y 1955, y 9 registros sonoros realizados por Pabel Lobanov en 1962.

\section{Estado de la cuestión}

Diversos autores se han aproximado desde el ámbito académico a la figura de Heinrich Neuhaus. El primer estudio relevante es la Tesis de Licenciatura defendida por su profesora asistente Tat'jana Chludova en 1955, en el Conservatorio Tchaikovsky de Moscú, titulada Pedagogičeskie principy prof. G. G. Nejgauza. Presentada aún en vida del maestro (antes, incluso, de que publicara El arte del piano), sirve hoy tan solo como una aproximación personal a su pensamiento docente. Las aportaciones de los últimos 50 años han dado pie a nuevos estudios, como el de Irina Marčenko en la Universidad de Ekaterinburgo (1999). Esta Tesis de Master, titulada La herencia pedagógica de $H$. G. Neuhaus en la formación profesional de los profesores de músi$c a$, es un trabajo de investigación breve (128 páginas) aunque relativamente reciente. Enfocada como estudio experimental sobre estudiantes de la Facultad de Pedagogía Musical, su orientación le aleja, no obstante, del ámbito interpretativo y pianístico.

Un tercer trabajo explora los fundamentos filosóficos y estéticos de su actividad. Se trata de la Tesis Doctoral presentada por Galina Crothers que lleva por título Heinrich Neuhaus. Life, philosophy and pedagogy. Este trabajo, que aborda su faceta pianística a través del análisis de dos de sus grabaciones, no toma en consideración, sin embargo, una parte considerable de su legado, compilado y publicado durante los últimos años, que incluye más de doscientos documentos inéditos u olvidados entre cartas, artículos y registros de sus clases y conferencias.

Todo este legado sí ha sido analizado en la investigación llevada a cabo desde la Universidad de Málaga, y que ha dado como fruto la Tesis Doctoral presentada en 2011 por Salve Márquez, titulada El legado pedagógico, intelectual y estético-mu- 
sical de un gran maestro: Genrich Gustavovič Nejgauz (1888-1964); investigación que a su vez da pie al presente artículo.

\section{Metodología}

El interés que ya en su época suscitó la metodología docente del profesor Neuhaus, y que ha continuado incrementándose con el paso del tiempo, justifica sobradamente la conveniencia de analizar este caso ciertamente singular de pedagogía musical. En consecuencia, la herramienta metodológica que hemos elegido ha sido el método del caso; y dentro de los tres modelos que en él definen Martínez y Musitu (1995), hemos optado por el modelo descriptivo, centrado "en el análisis, identificación y descripción de los puntos clave de un hecho o de una situación dada" (p. 34). En línea con el trabajo desarrollado por Huerta (2010), que "aborda la investigación de la enseñanza musical desde los parámetros metodológicos de los estudios de caso", hemos partido "de la observación y el análisis de los protagonistas, es decir, del profesorado y el alumnado que se ve inmerso en los procesos de enseñanza-aprendizaje" (p. 18).

En síntesis, nuestra investigación se ha desarrollado en tres fases:

A. Investigación documental: en la que se ha llevado a cabo un proceso minucioso de recopilación y análisis de fuentes primarias, en su mayoría disponibles únicamente en lengua rusa. Estas fuentes incluyen cartas personales, notas autobiográficas, artículos periodísticos, registros estenográficos y sonoros de sus clases y testimonios.

B. Registro y análisis de datos:

B.1 Catalogación de los registros audiovisuales. Una vez recopilados los 16 registros audiovisuales disponibles sobre sus clases (algunos, fílmicos; la mayoría, sonoros), hemos procedido a su catalogación y a la tabulación de sus contenidos. Concretamente se dispone del audio de sesiones de clase sobre las siguientes obras:

- Bach J. S., Preludio y fuga en do \# menor (Clave bien temperado vol. I).

- Beethoven, L. V., Sonata Op. 53 "Aurora” (Final).

- Brahms, J., Concierto $n^{\circ} 2$ para piano y orquesta, Op. 83.

- Debussy, C., La soirée dans Grenade (Estampas)

- Debussy, D., Jardins sous la pluie (Estampas)

- Metner, N., Dve skazki Op. 20.

- Mozart, W., Sonata en si bemol mayor K 333.

- Prokofiev, S., Visiones fugitivas, Op. 22.

- Scriabin, A., Preludio Op. 57, $n^{\circ} 1$ "Deseo".

- Chopin, F., Balada $n^{o} 1$

- Chopin, F., Balada $n^{\circ} 4$

- Chopin, F., Estudio Op. 10, $n^{\circ} 4$ (fragmento)

- Schuman, R., Sonata $n^{\circ} 2$ en sol menor, Op. 22.

La información de cada registro se ha recogido en cinco áreas de interés pedagógico: 
- Comunicación profesor-alumno.

- Estilo docente: carácter de las intervenciones pedagógicas.

- Modelo de clase: estructura de las sesiones y presencia de público.

- Contenido de las sesiones: ritmo, tempo, dinámica, expresión, articulación, técnica, armonía y forma.

- Procedimientos y estrategias docentes.

B.2 Análisis de testimonios. Se han estudiado en detalle los testimonios de 35 discípulos directos de Neuhaus a propósito de su estilo docente y su peculiar metodología pedagógica. Un caso particular ha sido el de su alumno Valerij Voskobojnikov, destacado representante de su línea pedagógica en occidente, y responsable de la Associazione Heinrich Neuhaus en Italia. Con él pudimos mantener una correspondencia fluida durante tres meses, y finalmente trabajar en su estudio de Roma durante cuatro días, momento en el que pudimos realizar una entrevista en profundidad.

C. Redacción y elaboración del texto. Tras someter a validación todo el material recopilado, su estudio y análisis nos ha conducido a la elaboración del presente artículo, con una exposición ordenada de los principales resultados que de él se desprenden.

\section{Análisis de datos}

A continuación, se analizan elementos característicos del método docente de Heinrich Neuhaus, articulados en cuatro categorías principales: la acción didáctica y comunicación con el alumno; la intervención pedagógica personalizada; el modelo, estructura y contenido de las sesiones de clase; y los principales procedimientos metodológicos.

\subsection{Acción didáctica y comunicación con el alumno}

Más allá de la evidente conexión entre Comunicación y Educación como disciplinas científicas y académicas, la riqueza que puede propiciar su mutua relación interactiva es, como señala Romero (1996, p. 163) "aún mínimamente valorada” por los docentes. Este profesor afirma con rotundidad que "los procesos de información y de comunicación resultan inherentes y son insoslayables a cualquier sistema de enseñanza, a la acción educativa que de él se derive y a los logros que se obtengan del mismo" (idem).

A su vez hemos de considerar, en el contexto de la enseñanza instrumental, el escaso tiempo dedicado a las sesiones de clase - una media de dos a tres horas semanales en el caso que nos ocupa - en relación al tiempo invertido en la práctica instrumental autónoma: según consejo del propio Neuhaus, "no menos de 4 horas diarias" (Neuhaus, 1952). Esto hace que el éxito de dicho proceso comunicativo entre docente y discente sea un asunto de la máxima importancia.

No obstante, la investigación en este ámbito es aún incipiente, y, como señalan Rostvall y West (2003, p. 4), "muy poco se sabe sobre las formas en las que interactúan los profesores de música y los alumnos". A estos autores se unen otros como 
Hallam (1998), que coinciden en destacar la distribución asimétrica de esta interacción, en la que el profesor asume el control de todo el proceso. Por su parte, Kurkul (2007), Levasseur (1994) y Mathers (2009) han centrado su investigación en el ámbito de la comunicación no verbal y su potencial para comunicar las intenciones musicales. A su vez, advierten sobre el desconocimiento por parte de educadores de estas técnicas, especialmente indicadas por su viabilidad para mantener la comunicación durante la interpretación musical del alumno.

Disponemos de referencias apuntadas por sus alumnos, algunas, ciertamente explícitas: “Жесты, интонации, мимика Нейгауза подчас были не менее выразительны, чем слова, которые он произносил. [Los gestos, la entonación, la mímica de Neuhaus a veces era no menos expresiva que las palabras que pronunciaba]" (Richter, 2007, p. 287)3; de ahí, que resulte "muy difícil plasmar su discurso en un papel" (Irina Naumova, en Richter 2007, p. 140).

Estos testimonios describen una actitud muy dinámica dentro del aula, con una amplia libertad de movimientos y un empleo eficaz de la comunicación no verbal durante la acción didáctica. Así lo recuerdan sus discípulos al describir, por ejemplo, la expresividad de sus manos cuando dirigía; un recurso que Neuhaus utilizaba intencionadamente y con gran eficacia para conducir la interpretación musical de sus alumnos.

Siento enormemente que no llegara a ser director de orquesta, además de por su inigualable talento musical, por sus dotes manuales. Tenía unas manos increíblemente expresivas. (...) A menudo, escuchando a los alumnos, dirigía; y si tocabas bajo las indicaciones de sus manos, no necesitabas ninguna explicación adicional. Estoy convencida de que hubiera sido un gran director de orquesta. (Fomina, 2007, p. 183).

También viva y elocuente resulta su comunicación verbal, en la que se observa un uso preciso, ingenioso e inteligente del lenguaje, y en la que cabría destacar su capacidad para despertar emociones.

Él exponía sus pensamientos con convicción, insistentemente, de diferentes formas; los repetía una y otra vez ante una nueva audiencia, y utilizaba cualquier pretexto para expresar sus ideas de la forma más clara, moderna y profunda posible, contagiando a todos su amor por la música. (Kremenštejn, 1984, p. 4).

Ciertamente, sus dotes como comunicador cautivan a su alumnado a través de la riqueza e interés de un discurso erudito, asentado en un amplio conocimiento multidisciplinar. Cualidades como la empatía, el sentido del humor y el ingenio aportarán espontaneidad y frescura a su estilo comunicativo, caracterizado por esa "combinación equilibrada entre información y persuasión” (Igor’ Žukov, en Richter 2007, p. 223).

\subsection{Intervención pedagógica personalizada}

En los últimos años, diversos estudios (Beheshti, 2009; Zhukov, 2007) han puesto de relieve un creciente interés por optimizar el proceso de enseñanza-aprendizaje a

Dado que en este artículo las citas en ruso son abundantes, traduciremos al español los textos originales en ruso sin copiarlos luego a continuación. Seguiremos esta norma con las demás lenguas. 
través de la adaptación metodológica al alumno, también en el contexto de la enseñanza instrumental.

Neuhaus se rebela contra la estandarización de los procedimientos metodológicos, que provoca una atención uniforme frente a demandas particulares del alumnado: “¿Por qué me veo obligado a citar hechos tan conocidos? Únicamente para sublevarme contra la vieja rutina pedagógica que coloca a todos los alumnos en el mismo plano y considera como rigurosas las leyes del desarrollo musical" (Neuhaus, 1958/1987, p. 112).

En esta intervención personalizada, la diagnosis se impone como punto de partida. Si bien no podemos hablar de un procedimiento sistemático, sí advertimos su observación cuidadosa de las características individuales de cada alumno, que incluye: condicionantes físicos como el tamaño y conformación de las manos, desarrollo cultural y artístico, grado de competencia técnica y educación auditiva. También presta especial atención a la disposición psicológica del alumno: estudia sus intereses, vigila y estimula su motivación e indaga en el posible origen psicológico de sus deficiencias. A partir de aquí, Berta Kremenštejn (2007, p. 27) define su intervención como una verdadera "reorganización psicológica". (Hemos traducido así el texto original que dice: "Психологической перестройки”. Obsérvese el matiz de la lengua rusa, ausente en la traducción española, que implica reestructuración).

En este proceso de intervención personalizada, Neuhaus no solo utilizará diferentes estrategias metodológicas. También regulará cuidadosamente el grado de intervención en el desarrollo de la personalidad artística de sus alumnos. Según sus propias palabras: "cuanto más maduro (más talentoso) e independiente sea el alumno, hay menos necesidad de que el profesor intervenga en su trabajo" (Neuhaus, 1962/2008, p. 426).

Con los alumnos bien dotados he sido habitualmente más liberal. Por eso Emile Gilel's [uno de sus más destacados alumnos] ha podido reprocharme el poco tiempo y los pocos consejos que le he dado. Es verdad que, más tarde, él ha reconocido que yo le indiqué el camino de la independencia. (Neuhaus, 1958/1987, p. 169)

De hecho, en las grabaciones encontramos expresiones del tipo "no te molestaré" o "he decidido no intervenir" (Kremenštejn, 2007, p. 31; Bulatova, 2007, p. 9) con alumnos que presentan una significativa solvencia técnica y musical. Según la profesora Kremenštejn, esta actitud especialmente lacónica podría verse acompañada a su vez de una dedicación más limitada en el tiempo, frente a una actuación más prolongada con alumnos menos dotados. Así también lo expone Neuhaus al recordar su trabajo con Richter sobre la Sonata en si menor de Liszt: "En todo esto se nos fueron unos 30-40 minutos. Y por lo general con mis alumnos trabajo sobre esta Sonata entre 3-4 horas durante varias sesiones de clase" (Neuhaus, 1960, p. 374).

Tras el diagnóstico inicial, la selección de un determinado programa se constituye como elemento significativo en su intervención personalizada. No obstante, en ningún caso renunciará al que considera un objetivo principal: la interpretación artística del repertorio elegido. Por ello insiste en la importancia de una cuidadosa selección que no exceda las posibilidades reales del alumno.

Ciertos profesores conscientes y celosos tienen tendencia, con toda buena fe, a transformar la literatura musical en manuales escolares. Cuando discuten la utili- 
dad que puede aportar a su alumno la Appassionata, me encoleriza y me dan ganas de preguntarles cuál es la utilidad que el alumno en cuestión puede aportar a la Appassionata. (Neuhaus, 1958/1987, p. 186).

\subsection{Las clases}

\subsubsection{Modelo "master class"}

El conjunto de testimonios y grabaciones disponibles revela una característica muy singular de estas sesiones: el modelo master class frente a la tradicional enseñanza individualizada. Es importante señalar, no obstante, que estas sesiones de tipo master class no lo son en sentido estricto, en cuanto no son planificadas, organizadas y publicitadas previamente, ni tienen carácter de actividad puntual y complementaria. Por otro lado, entre el público encontramos al grupo de alumnos de Neuhaus, que asisten asiduamente a las clases de sus compañeros como parte de la dinámica general impuesta por el maestro.

Heinrich Neuhaus, por cierto, exigía a sus alumnos asistir a todas las clases. Y en la medida en que nos lo permitiese nuestro horario, que escuchásemos [...]. De hecho, algunos estudiantes de otros profesores, cuando empezaban a trabajar sobre una nueva pieza, trataban de averiguar si algún alumno de Neuhaus la estudiaba y qué día la tocaría en clase, y luego venían y se sentaban con la partitura y el lápiz delante. (Fomina, 2010, p. 24).

Se trata, pues, de un modelo mixto entre la master class y el modelo de grupo, adoptado de forma espontánea e integrado en el marco y frecuencia habitual de las sesiones de clase. Podríamos decir que aparece como consecuencia lógica de dos factores: la clara y manifiesta preferencia del maestro por esta modalidad, y la indiscutible curiosidad e interés que despierta su actividad entre los estudiantes de su época. Imágenes del público asistente a sus clases y testimonios en esta dirección pueden encontrarse en Tichonov (2008, p. 4'36")

En opinión de Neuhaus, firme defensor de este carácter abierto de las clases, el modelo es especialmente fructífero para alumnos y profesores, pues favorece un intercambio de experiencias que es esencial en la formación superior del artista.

Hoy observamos que la instrucción one-to-one, en la intimidad del aula a puerta cerrada, se ha perpetuado como modelo tradicional en conservatorios y otros centros de enseñanza instrumental. El modelo de grupo no se adopta más que en determinados estadios iniciales de la formación, o bien como un complemento puntual durante la formación superior. Sin embargo, recientemente algunos investigadores (Daniel, 2004; Gaunt, 2008) han cuestionado la eficacia de este sistema altamente individualizado:

La intimidad de la relación individual y la dinámica de poder que en ella se establece sugiere que, si bien se puede obtener mucho de la detallada y compartida reflexión durante la acción que permite esta instrucción individualizada, también puede inhibir el desarrollo de la autorresponsabilidad y de una voz artística propia, la cual es tan preciada por los profesores. (Gaunt, 2008, p. 240). 
Frente a esa tradicional relación maestro-aprendiz, que ha dominado el panorama de la educación instrumental, y el excesivo celo con el que muchos pedagogos han impartido sus enseñanzas, el planteamiento de Neuhaus resulta ciertamente innovador. Quizás por ello, en su momento fue acogido con cierta prevención, y algunos colegas no vieron en él más que un exceso de vanidad personal:

Esto era espectáculo. Un espectáculo brillante e ingenioso, con un brillante dominio del discurso, del lenguaje. Todo esto creaba un aura que causaba la admiración de todos. En mi opinión, en todo esto había más teatro que pedagogía real. Por otra parte, la verdadera pedagogía es muy difícil de mostrar públicamente. (Perl'man, 1992/2008, p. 263).

Más allá de esta supuesta egolatría, en su preferencia por este modelo advertimos una profunda convicción sobre sus beneficios. Así, en 1933, en una publicación interna del Conservatorio, apareció un artículo suyo titulado "Sobre la experiencia de compartir experiencias". Allí manifiesta una encendida defensa de la que él denomina "política de puertas abiertas" (Neuhaus, 1933/2008, p. 182), basada en la intercomunicación como fuente de enriquecimiento dentro de la institución académica. Con este objetivo, aboga por un constante intercambio de opiniones, puntos de vista y experiencias a través de la organización de diferentes foros de discusión en los que se produzca esta comunicación directa entre profesores y alumnos. En esta línea, insta al alumnado a adoptar una postura activa e investigadora, alentándole a asistir como público oyente a las clases de interpretación de diferentes profesores: "No hay secretos para nadie, no tenemos secretos, 'política de puertas abiertas' declarada oficialmente, pero qué pocos son los que 'entran y salen' por esas puertas" (Neuhaus, 1933/2008, p. 182).

\subsubsection{Estructura y contenido}

Estas sesiones de clase presentan un marcado carácter asistemático en el que, no obstante, podemos identificar ciertos patrones recurrentes.

En primer lugar, debemos determinar sus límites, pues dado su contexto abierto y público, los alumnos reciben unas sesiones de clase como parte del colectivo oyente, y otras en las que protagonizan la interpretación que servirá de base en el desarrollo de la sesión. Nos referiremos a estas últimas como "clase individual" o como "sesión de clase" propiamente dicha.

Su duración y horario será flexible y asistemático (cfr. Vedernikov, 2000; Voskobojnikov 2011). Neuhaus trabaja en su aula durante un horario semanal previamente definido. Los alumnos deciden libremente el día en el que se encuentran preparados para tocar delante del maestro; mientras, asisten a sus clases en calidad de oyente, y trabajan quizás bajo la dirección de los profesores asistentes que colaboran con el maestro.

Varios testimonios nos hablan de esta flexibilidad en el horario: "A veces estaba inspirado (esto dependía del alumno y de la obra), y no se veía el final de la clase; sin mirar el reloj, trabajaba completamente ajeno al paso del tiempo, dejándose llevar entusiasmado" (Gornostaeva, 2007a, p. 189). No obstante, y salvo casos puntuales, Kremenštejn (1984) señala una media de entre dos y tres horas semanales de clase individual para cada alumno con el maestro. 
La sección principal de estas clases gira, por lo general, en torno a la interpretación del alumno. En ella observamos los procesos de diagnóstico, evaluación, y orientación, descritos por Zhukov (2004) en su particular estudio de caso.

El comportamiento típico fue que el estudiante tocaba una pieza o parte de una pieza, y el profesor evaluaba la interpretación del alumno, diagnosticaba problemas y sugería soluciones a los mismos. Las directrices del profesor, las explicaciones, las preguntas y respuestas también desempeñaban un papel importante en las estrategias de enseñanza. (Zhukov 2004, p. 245).

No obstante, otras sesiones se apartan radicalmente de esta dinámica: "Una vez traje a clase un libro sobre efectos especiales (yo entonces era un ávido aficionado al cine). Heinrich Gustavovich me arrebató el libro de la mano y... ise acabó la lección!" (Lev Naumov, en Richter 2007:138). Su discípulo continúa el relato detallando la interesante e improvisada exposición que realizó el maestro sobre el arte cinematográfico, en presencia de unas veinte personas que habían acudido como público.

Otro testimonio sobre su flexibilidad -y su capacidad para adaptarse a las necesidades del alumno- nos lo ofrece su estudiante Vera Gornostaeva (2007b), quien en cierta ocasión acudió a clase del maestro con la intención de escuchar a sus compañeros, pero lo encontró solo. Al confesarle sus problemas en el estudio de una mazurka de Chopin,

[...] él tomó el volumen de las mazurkas, lo puso en el piano. Comenzó a tocarlas una tras otra a primera vista, disfrutando francamente de la música. Más de la mitad las tocó casi de memoria, durante mucho tiempo, dos horas en una clase vacía. Yo le pasaba las páginas, permanecía de pie y escuchaba. Y solo cuando se abrió la puerta y alguien entró, él cerró las partituras, me miró y preguntó: ¿Has entendido? (Gornostaeva 2007b, p. 197).

Según Berta Kremenštejn (2007), cada obra era objeto de estudio profundo en clase durante dos o tres sesiones, tras lo cual, quedaba sujeta al trabajo independiente del alumno, que habría de presentarla en su próxima actuación en público. Durante estas dos o tres sesiones, Neuhaus no se limitaba a realizar una revisión y seguimiento del progreso y cumplimiento con respecto a las indicaciones previas. Por el contrario, dedicaba cada una de ellas a examinar la interpretación desde un nuevo punto de vista, con el objetivo de ampliar las fronteras y horizontes artísticos del alumno, y dotarle así de herramientas precisas para desenvolverse con autonomía.

En lo relativo al contenido, es frecuente observar en las clases un enfoque interdisciplinar con abundantes comparaciones entre las técnicas y procedimientos utilizados en diferentes disciplinas artísticas. Un ejemplo de ello puede oírse en la grabación de una de sus clases impartidas a Aleksey Nasedkin en 1962. Al comienzo de la Variación VII, en el minuto 2'26", Neuhaus establece una interesante conexión en términos expresivos entre esa pieza y los paisajes de invierno presentes en la pintura de T. Reinhart. Concretamente, estimula la imaginación del alumno con una imagen nocturna de los árboles agitándose a causa del viento.

En lo relativo al contenido, también Crothers (2010) abunda en esta amplitud de enfoque como una de las claves en el éxito de su metodología. 
El hecho de que él trascendiera los límites de la comprensión tradicional de la pedagogía del piano fue otro motivo de su inmenso éxito como profesor. La enseñanza de Neuhaus fue una síntesis de diferentes disciplinas. En su enseñanza no solo empleó su amplio conocimiento sobre música y arte con la continua sugerencia de analogías, sino que también se basó en sus conocimientos sobre filosofía y psicología de la actividad artística. (Crothers, 2010, p. 314).

\subsection{Procedimientos metodológicos}

Neuhaus conduce la sesión de forma absolutamente flexible e improvisada, al tiempo que despliega importantes dosis de creatividad en la elección de los métodos docentes. Estudiaremos sus procedimientos y estrategias didácticas empleadas durante el proceso enseñanza-aprendizaje, con el fin de que el alumno descubra, asimile y sistematice conocimientos y, a su vez, desarrolle ciertas competencias y habilidades.

\subsubsection{Conducción y modelado}

Uno de sus métodos principales era trabajar sobre esos "límites": dónde hacía falta "un poquito más", "un poquito menos", dónde ya habíamos sobrepasado el buen gusto o, por el contrario, dónde no habíamos llegado y resultaba una interpretación fría y poco interesante. (Voskobojnikov, en Márquez, 2011, p. 525).

La ejecución del alumno aparece de forma generalizada como elemento que articula el discurrir de la sesión. Se observa un proceso retroalimentado en el que el maestro conduce e interrumpe al alumno con el objetivo de modelar su resultado sonoro en el instrumento, al tiempo que este adapta y reanuda su ejecución conforme a las indicaciones recibidas.

Para conducir la ejecución del alumno, Neuhaus utiliza diversos procedimientos. Uno de ellos es realizar demostraciones simultáneas desde un segundo piano, seleccionando, y en ocasiones enfatizando, aquellos parámetros sobre los que pretende intervenir. De esta forma el alumno intentará ajustar su realización a la percepción externa. Otras veces el maestro utilizará su propia voz para cantar o formular instrucciones verbales breves y concretas, del tipo "más piano" o "no corras", que sin llegar a interrumpir el discurso musical alerten al alumno e influyan en su ejecución. Finalmente, Neuhaus utilizará también el lenguaje sonoro no verbal para conducir al alumno, con palmadas, percusiones, y otros sonidos como el siseo, junto a una gestualidad ciertamente expresiva.

Las interrupciones son en su mayoría provocadas por el maestro, que da paso a una explicación más profunda sobre algún elemento particular; ocasionalmente aparecen precedidas por un breve comentario, a modo de feed back. Estas indicaciones breves dejan paso a observaciones más amplias y detalladas, a veces acompañadas por demostraciones con el instrumento o con la voz. "Un característico método muy querido y utilizado por Neuhaus en sus clases - afirma su profesora asistente T. Chludova $(1955$, p. 7) - era argumentar a sus alumnos por qué este y no aquel episodio, este o aquel tema, por qué resultan tan conmovedores" Su contenido y nivel de concreción es igualmente variado, $\mathrm{y}$ abarca desde aspectos precisos sobre técnica y expresión (ritmo, dinámica, articulación, digitación, estructura, etc.), hasta 
comentarios más generales sobre ediciones, versiones de la interpretación e incluso recuerdos personales. Numerosos ejemplos de esta dinámica pueden escucharse en las 15 grabaciones publicadas por Andrej Chitruk (2008).

Un ejemplo paradigmático es la clase impartida en 1962 a Esther Ellin sobre La Soirée dans Grenade, de C. Debussy. En ella, a propósito del ritmo de danza, Neuhaus llama la atención de su alumna sobre la importancia y naturalidad de las sutiles desviaciones sobre el patrón de una métrica exacta, y compara estas desviaciones con aquellas presentes en las medidas arquitectónicas del Partenón o con la particular ordenación de los elementos de la tabla periódica de Mendeléyev.

El comportamiento del alumno juega un papel determinante en el desarrollo de la sesión, pues gran parte de la misma está protagonizada por su propia ejecución al piano. En el marco de esta ejecución, permanentemente interrumpida y reanudada, en un proceso absolutamente fluido y coordinado, el alumno formula ocasionalmente preguntas y comentarios, y responde a cuestiones planteadas por el maestro. Esta comunicación verbal se revela complementaria al proceso comunicativo establecido entre él y Neuhaus a partir de su propia ejecución al piano y de las observaciones e indicaciones del maestro.

\subsubsection{Demostraciones al piano}

En 1961, ante el progresivo deterioro que sufre como consecuencia de la lesión en su mano, el maestro pierde agilidad en los dedos y se siente fuertemente limitado en su actividad docente. Al no poder mostrar de forma práctica sus intenciones a los alumnos, llega a plantearse seriamente el abandono del magisterio. Tal frustración revela la importancia y frecuencia de estas demostraciones en su acción didáctica.

Considero un grave error, que perjudica a la actividad pedagógica, el hecho de que la mayoría de los profesores no perfeccionan en absoluto su ejecución. [...] Felizmente, en el transcurso de los últimos años, la situación ha mejorado y los profesores que se presentan ante el público son cada vez más numerosos. (Neuhaus, 1958/1987, p. 187).

En el análisis de los registros de sus clases se han observado principalmente tres tipos de interpretaciones, con diferentes finalidades:

1. Demostraciones con función ilustrativa, en las que el maestro materializa su propia interpretación o bien expone alguna otra variante, a modo de ejemplo. Estas demostraciones no se realizan de forma exclusiva sobre la pieza objeto de estudio. Con frecuencia, Neuhaus recurre a su amplio conocimiento de la literatura musical para ilustrar con ejemplos diversos sus explicaciones. Como muestra de este primer tipo, señalaremos la interpretación que Heinrich Neuhaus realiza de Traurnyj marš [Marcha fúnebre Op. 31, $\mathrm{n}^{\mathrm{o}}$ 2] de Nikolái Médtner y del 3.er movimiento de la Sonata $n^{\circ} 2$ en Si bemol menor, Op. 35 (marcha fúnebre), en el transcurso de una clase dedicada a la Sonata para piano $n^{\circ} 12$ en La bemol mayor, Op. 26 de Beethoven, con objeto de establecer una comparación entre el carácter de su tercer movimiento (una marcha fúnebre) y otras compuestas por diversos autores (Neuhaus, 1937/2008, p. 206). Otro ejemplo de este tipo de demostraciones con función ilustrativa puede verse en un fragmento de una clase impartida a Margarita Fedorova, Stroeva (1945, p. 13'58'). 
2. Demostraciones con función de dirección. Son un caso particular de conducción realizado a menudo desde un segundo instrumento y de forma simultánea a la ejecución del alumno. El estudiante percibe las desviaciones entre su ejecución y la del maestro y, en su intento por amoldarse a ella, reconstruye sobre la marcha su propia interpretación, estableciendo así nuevos equilibrios de tempo, entonación, planos sonoros, ritmo, etc. Estas demostraciones son con frecuencia parciales; es decir, el maestro se limita a resaltar momentáneamente una única parte del texto: una sola voz, un determinado acompañamiento, algún diseño rítmico, etc. Un ejemplo de ello lo encontramos en el minuto 3' 06" del siguiente fragmento de una clase impartida a E. Ellin sobre la Balada n 4 de Chopin, en 1962.

3. Demostraciones con función desveladora. Intervenciones cuya función es la exposición ante el alumno de algún elemento concreto que quedará al descubierto, en ocasiones de forma exagerada, alterando significativamente otros parámetros de la ejecución; por ejemplo, ejecutar solo el acompañamiento con una dinámica exagerada, prescindiendo de la melodía. En otro momento de la clase anterior, en el minuto 7' 13', podemos escuchar un ejemplo de estas demostraciones en las que el maestro acompaña su explicación con una ejecución del bajo. En esta línea, Neuhaus incluso realiza ocasionalmente una imitación caricaturizada de la interpretación llevada a cabo por el alumno, con el fin de exponer claramente aquellos aspectos que debe modificar.

\subsubsection{El lenguaje figurativo}

Para Neuhaus la imagen estética de la obra musical es la verdadera piedra angular sobre la que construye todo el proceso de enseñanza-aprendizaje: "La música vive en nosotros, en nuestro cerebro, en nuestra conciencia, en nuestro sentimiento, en nuestra imaginación. Su sede es el oído" (Neuhaus, 1958/1987, p. 23). Estas palabras aluden directamente al llamado "oído interior" como centro encargado de elaborar la representación mental de la música, forjada a partir de la propia imaginación o como resultado de una previa percepción fijada en la memoria.

El interés de las corrientes pedagógicas por el oído como elemento clave en la formación pianística aparece con cierta entidad en la Unión Soviética de la mano de teóricos como G. M. Kogan, L. A. Barenboim y G. P. Prokofiev. Precisamente en el prólogo a la obra de L. A. Barenboim (1937), Neuhaus elogia el interés de su primer capítulo: "La educación del pensamiento musical". En este texto, Barenboim esquematiza este proceso subyacente a la interpretación pianística en clara coincidencia con las ideas de nuestro autor (1937/2007, p. 14).

Según los postulados de Neuhaus, a partir de las capacidades cognitivas del alumno, de sus conocimientos previos y de su particular desarrollo cultural y artístico, este elaborará una representación mental subjetiva que guiará los procesos motrices implicados posteriormente en su ejecución musical. "H. G. Neuhaus condujo a sus alumnos desde el interior hacia el exterior, al tiempo que la pedagogía tradicional iba desde el exterior (es decir, de la técnica) hacia el interior" (Marčenko, 1999, p. 23).

Según este planteamiento, si la realización práctica en el teclado está condicionada por la representación mental de la música, parece lógico pensar en una intervención didáctica que opere en este nivel. Estas precursoras ideas del maestro han encontrado un amplio respaldo en la literatura científica posterior. 
En cuanto a la interpretación musical, por ejemplo, está comprobado que la “imagen" mental que tiene un músico de una melodía dirige cómo él o ella en realidad la interpretará (p. ej. Clarke, 1993; Gabrielsson, 1999; Krumhansl, 1992; Woody, 1999). Por lo tanto, un profesor puede hablar sobre el tratamiento de una melodía de formas diferentes, e incluso modelarla en repetidas ocasiones, pero hasta que no haya un cambio en la representación interna que tiene el alumno de la melodía (p. ej., de cómo debería sonar), no hay motivos para esperar un cambio fiable en su interpretación. (Woody, 2006, p. 125).

Es aquí donde el lenguaje figurativo se revela como una herramienta ciertamente apropiada y eficaz, pues proyecta una serie de imágenes que actúan como fundamento sensorial de la abstracción.

El lenguaje no es una esfera mental en sí mismo; no tiene otra sustancia que los significados de las imágenes a que se refieren las palabras. Y las "actividades proposicionales" como la abstracción deben por fuerza apoyarse en el único universo mental de que disponemos, el mundo de los sentidos. (Arnheim, 1993, p. 32).

El profesor Arnheim afirma más adelante: "Desde la infancia, nos acostumbramos espontáneamente a pensar y a hablar con metáforas porque la concreción de acontecimientos que se pueden ver sirve para ilustrar la dinámica de otros sucesos que no son tan directamente visibles" (1993, p. 47). Y, a modo de conclusión, sintetiza: "Apenas se produce enseñanza ni aprendizaje en ningún campo de estudio sin el uso práctico de las imágenes" (1993, p. 53).

A pesar de que el lenguaje figurativo ha sido tradicionalmente utilizado en la enseñanza instrumental como estrategia didáctica, todavía "tenemos poca comprensión sobre el uso actual del lenguaje metafórico, la importancia de la receptividad a la metáfora en los estudiantes y las habilidades de los profesores para encontrar la metáfora adecuada para cada alumno en el momento preciso y la situación concreta" (Schippers, 2006, p. 214). Quizás por todo ello, interesa estudiar el uso que de él han hecho destacados pedagogos en el ámbito de la enseñanza instrumental.

Neuhaus despliega un generoso uso del lenguaje figurado en el que encontramos abundante presencia de tropos como la metáfora, el símil, la ironía y la paradoja. Defiende abiertamente la eficacia de este procedimiento como medio para influir en la representación mental del alumno y, a partir de ahí, intervenir directamente en el resultado sonoro de su ejecución:

Nosotros, profesores, hemos recurrido constantemente a las metáforas para definir la forma de obtener del instrumento la sonoridad deseada. [...] Estas comparaciones, tan aproximadas como se quiera, son sin embargo útiles, pues despiertan la imaginación del alumno y, unidas a la demostración práctica, actúan sobre su oído, sobre su aparato motor, sobre su ejecución. (Neuhaus, 1958/1987, p. 70).

En un esfuerzo por entender y sistematizar el uso docente de esta estrategia, el profesor Schippers distingue entre una utilización del lenguaje metafórico como referencia concreta hacia el contenido estético, y otra más dirigida hacia la instrucción técnica. Finalmente, subraya su uso más frecuente, como combinación de las opcio- 
nes anteriores: "utilizado de una manera que combina la instrucción técnica con la intención estética" (2006, p. 211).

Neuhaus utiliza a menudo estas representaciones con la clara intención de provocar en el alumno una sensación interna del movimiento. Berta Kremenštejn (1984) recuerda un ejemplo muy elocuente: el maestro pretendía lograr del alumno un sonido de muy reducido nivel dinámico ( $p p p)$ durante la ejecución de un trino, a través de la siguiente imagen:

Imagínese. Usted camina junto a una pared sobre un suelo irregular en completa oscuridad. Sus ojos están tapados, y los brazos estirados hacia la pared para no perderla, la sensibilidad de los dedos "ingrávidos” (¡en ellos se concentra toda comunicación con el exterior!) le prepara para sortear cualquier dificultad y advertir el peligro. (Kremenštejn 1984, p. 31).

Con base en las propiedades de la dinámica perceptiva señaladas por Rudolf Arnheim, a través de esta visualización el alumno entra en "resonancia" (1993, p. 47) con la dinámica que transmite esa imagen, de forma que reproduce interiormente y de forma natural las tensiones de esa acción visualizada. En el ejemplo anterior, durante la ejecución del movimiento, esto podría traducirse en una mínima pérdida de contacto entre la superficie del teclado y la punta de los dedos, junto a un movimiento rotatorio de amplitud reducida.

Analizando los numerosos ejemplos con que Neuhaus ilustra sus explicaciones, podemos hablar de cinco tipos de representación, según apelen al ámbito auditivo, visual, cinestésico, emocional o racional.

a) Auditivo: las figuras sugieren cualidades sonoras o evocan un efecto sonoro concreto. Encontramos en sus clases ejemplos como "plata tintineante" o "pesadas gotas de oro" (citado en Kremenštejn, 1984, p. 30); también numerosas referencias a un sonido "brillante", "seco", "opaco", "cálido", etc. Precisamente un contemporáneo de Neuhaus — Otto Rudolf Ortmann_-, realizó numerosas investigaciones sobre la percepción sensorial del sonido. Recientemente, David Gonzol (2004) llevó a cabo una revisión de los hallazgos de Ortmann, y planteó algunas cuestiones sobre la enseñanza de estos "atributos" del sonido, renombrados por él como "qualities".

Siguiendo la exposición de Gonzol, en un primer nivel estarían tres dimensiones medibles físicamente: la frecuencia, la intensidad y la duración. En el segundo nivel, se encontrarían estas mismas dimensiones tal y como son percibidas por el oído humano, en la combinación necesaria entre ellas. Esta combinación daría lugar, en un tercer nivel, a la percepción de una serie de cualidades que no son medibles físicamente: por ejemplo, la calidez, la brusquedad o la brillantez del sonido, si bien se verían alteradas con la simple variación en el valor de una de las tres dimensiones primarias.

En relación a la ciencia, podríamos enseñar que las tres dimensiones del sonido operan en combinaciones que nosotros oímos como frecuencia, intensidad, duración y especialmente el timbre. Aunque Ortmann no fue más allá, es el primero en explicar con precisión este concepto. Y, a partir de su explicación, hablamos legítimamente de cualidades en términos descriptivos: bajo, redondo, claro, suave. Esto no quiere decir que cualquier término deba ser (o pueda ser) absolutamen- 
te preciso. Pero mientras sea suficientemente cabal para la ocasión, un término como "más bajo", "más redondo", "más claro" y "más suave” puede ser el más apropiado, como Ortmann firmemente instó a propósito de la pedagogía del piano. (Gonzol 2004, p. 172).

En su opinión, este segundo nivel es esencial en el aprendizaje de la música y la enseñanza de la técnica. En el tercer y último nivel se encontrarían las asociaciones; entraríamos en el terreno de la imaginación musical, y su enseñanza es vinculada directamente con la expresividad. Es precisamente en este segundo y tercer nivel en el que podemos situar la mayoría de las indicaciones que Neuhaus utiliza en las clases, en su intento por modificar el resultado sonoro y provocar la sensación interna del movimiento.

b) Visual: las figuras se orientan a la organización espacial y la geometría del movimiento. Por ejemplo, al hablar sobre la funcionalidad de los dedos como soporte o apoyo del peso, Neuhaus afirma: "Son columnas o más bien arcos bajo la bóveda de la mano" (Neuhaus, 1958/1987, p. 96), con una clara alusión a su firme verticalidad sobre el eje horizontal del teclado.

c) Cinestésico: las figuras desvelan la dinámica del movimiento. Uno de los ejemplos especialmente ilustrativos lo encontramos al estudiar la problemática de los saltos y desplazamientos en el teclado. Neuhaus (1958/1987) describe analíticamente la geometría del movimiento: la mano ha de realizar un desplazamiento en forma de arco. La bajada o caída ha de ser finalmente vertical. Para ello aconseja un ligero movimiento hacia sí, evitando una pulsación en oblicuo. A continuación, acompaña su descripción con una imagen de alto contenido metafórico, que enfatiza la dinámica de fuerzas implicadas en el movimiento:

A veces, la mano debe bajar rápidamente sobre las teclas y levantarse como el águila con su presa cuando la agarra y toma vuelo. Si la mano cae inerte como una piedra, se hiere a sí misma y el piano también grita de dolor. (Neuhaus 1958/1987, p. 128).

El maestro completa esta imagen con los términos "coger una nota" en vez de "caer sobre una nota"; "la mano se asienta", "baja" o "agarra", en lugar de "la mano cae". De esta forma, implícitamente describe e intenta transmitir - o, en palabras de Arnheim, hacer "resonar" — en el aparato motor del alumno la dinámica del movimiento en su punto de llegada ante el contacto de los dedos con el teclado. En la misma línea, ante la necesaria soltura del brazo en dichos desplazamientos, utiliza esta expresión: "Como las alas impulsan a los pájaros, a los ángeles, etc., en el sitio donde nos crecen los brazos, yo admito el término "volar"” (Neuhaus, 1958/1987, p. 129).

d) Emocional. Encontramos con frecuencia imágenes que apelan al estado emocional que debe adoptar el intérprete. Citaremos dos ejemplos extraídos de sus clases: el primero, sobre el tercer movimiento de la Sonata Op. 101 de Beethoven, al recomendar a un alumno: "Esto debería ser tocado casi en actitud de oración" (Neuhaus, 1938/2007, p. 125); el segundo, cuando habla sobre la Marcha fúnebre Op. 31 $\mathrm{n}^{\mathrm{o}}$ 2, de Nikolái Médtner, en los siguientes términos: "Aquí huele a cadáver, y esta sensación crece cada vez más, y después... nada, solo tierra” (Neuhaus 1937/2008, p. 
206). (Hemos traducido así el texto original que dice: “тут прямо трупом пахнет, и это настроение все растет, растет и потом -ничего, земля". Nótese la connotación afectiva del término настроение, referida al estado psíquico del individuo).

e) Racional. En ocasiones, apela a la reflexión racional del alumno a través de ciertas imágenes o asociaciones. Utiliza este recurso, por ejemplo, en otra de sus clases, de la Sonata $n^{\circ} 28$ de Beethoven: "En Beethoven encontramos a menudo pasajes donde hay pocas notas, pero mucho contenido, como un orador que presenta un montón de grandes ideas brevemente, sin 'adornos' en su oratoria" (Neuhaus, 1938/2008, p. 233).

Esta riqueza en el uso del lenguaje figurativo ofrece un interesante potencial didáctico. Su utilización como estrategia docente en el aula persigue la estimulación de la imaginación y de la fantasía del alumno, el desarrollo de su capacidad expresiva, la comprensión y asimilación de la idea representada, y una reorganización inconsciente a nivel mecánico de los elementos del aparato motor implicados en la ejecución.

\section{Conclusiones}

La metodología docente del profesor Neuhaus presenta características ciertamente innovadoras que adelantan algunos de los recursos pedagógicos que hoy se están recuperando. Algunas de esas características han sido ya apuntadas sucintamente en investigaciones previas: su concepción de la pedagogía como proceso creativo, la influencia psicológica emocional y artística del profesor sobre el alumno, y el énfasis en adoptar diferentes enfoques metodológicos en función de la realidad individual del alumno (Viktor Del'son, 1966; Berta Kremenštejn, 1984; Galina Crothers, 2010). En esta investigación han aflorado otros rasgos muy personales en su estilo docente que consolidan la dimensión artística y creativa de su pedagogía. Aparecen así algunos elementos clave, como su aproximación interdisciplinar al hecho musical, basada en una educación artística integral que involucre la dimensión cognitiva, estética, creativa y expresiva, y el carácter flexible, asistemático y con importantes dosis de improvisación de las sesiones de clase.

En su actividad docente, Neuhaus se revela como un competente comunicador, cuyo estilo pedagógico se caracteriza por una gran expresividad y fuerza comunicativa. Se aprecia un uso preciso, ingenioso y eficaz del lenguaje, así como plena consciencia de la trascendencia del aspecto comunicativo en la labor docente. Su magistral uso del lenguaje figurativo, con asociaciones altamente creativas y poco convencionales, acaba configurando una estrategia docente de uso frecuente y gran influencia.

La imagen estética se confirma como elemento comunicativo fundamental en su concepción de la interpretación pianística, y como punto de partida en el proceso de enseñanza-aprendizaje. En este sentido, su intervención pedagógica está basada en la activación del oído interior, como centro encargado de elaborar la representación mental de la música, y en una doble aproximación intelectual y emocional al contenido estético.

Neuhaus huye de los estándares docentes y considera las particularidades individuales como punto de partida en el diseño de la intervención pedagógica, apostando 
por una mínima intervención para favorecer la independencia artística del alumno. La adaptación a las particularidades del alumno se lleva a cabo a través de los siguientes elementos:

- Elección del repertorio.

- Nivel de concreción en las indicaciones.

- Contenido, duración y organización de la sesión de clase.

En su particular fusión entre tradición e innovación encontramos procedimientos metodológicos muy frecuentes, como la conducción y el modelado, las demostraciones al piano (con función ilustrativa, de conducción y desveladora), y un recurrente uso plástico del lenguaje figurativo.

Su planteamiento resulta asimismo actual e innovador en la medida en que se adelanta a su tiempo: atiende a problemas educativos que hasta fecha reciente no han sido suficientemente tratados, y sugiere para ellos soluciones y estrategias docentes que han sido posteriormente refrendados por la investigación en pedagogía musical. Un caso paradigmático es su decidida apuesta por un modelo mixto entre la master class y la clase en grupo que estimule el intercambio de experiencias y aprendizajes entre el alumnado, a la par que evita su aislamiento, un asunto reivindicado por teóricos de la pedagogía musical en fecha muy reciente.

Una vez desvelada la metodología docente de Neuhaus, y una vez analizadas sus características más singulares, cabe preguntarse si un estilo de enseñanza como el aquí descrito es aplicable a cualquier docente. La respuesta no es fácil, aunque sí podemos apuntar una doble salida. Por una parte, este método es tan personalista y se basa en un temperamento tan creativo, empático e intuitivo que podría no acomodarse a los diversos caracteres de los docentes musicales. Por otra, la riqueza de su método es tal que sin duda puede mejorar -acaso parcialmente- las estrategias docentes de la práctica totalidad de los profesores de música. En mayor o menor medida -al menos eso pensamos- la metodología docente de Neuhaus puede inspirar a las futuras generaciones de maestros de la enseñanza pianística y musical en términos generales.

\section{Referencias bibliográficas}

Álvarez, C., \& San Fabián, J.L. (2012). La elección del estudio de caso en investigación educativa. Gazeta de Antropología, 28(1). Disponible en http://hdl.handle.net/10481/20644

Arnheim, R. (1993). Consideraciones sobre la educación artística. Barcelona: Paidós.

Barenboim, L. A. (1937/2007). Fortepiannaja pedagogika [La pedagogía del piano]. Moscú: Izdatel'skij dom «Klassika-XXI».

Beheshti, S. (2009). Improving studio music teaching through understanding learning styles. International Journal of Music Education, 27 (2), 107-115. doi: $10.1177 / 0255761409102319$.

Bulatova, L. B. (2007). V tvorčeskoj masterskoj Genricha Nejgauza [En el estudio de Heinrich Neuhaus]. Moscú: Federal'noe agentstvo po kul'ture i kinematografii, Rossijskaja akad. muzyki im. Gnesinych, Obščestvennyj fond «Russkoe ispolnitel'skoe iskusstvo».

Chitruk, A. F. (2008.), G. G. Nejgauz. Doklady i vystuplenija. Besedy I seminary. Otrkytye 
uroki. Vospominanija o G. G. Nejgauze [G. G. Nejgauz. Conferencias y discursos. Conversaciones y seminarios. Clases abiertas. Recuerdos sobre G. G. Nejgauz]. Moscú: Deka-VS.

Chludova, T. A. (1955), Pedagogičeskie principy prof. G. G. Nejgauza, Teoret. čast. isp. kand. Dissertacii, MGDOLK im. Čajkovskogo, Moscú.

Crothers, G. (2010), Heinrich Neuhaus. Life, Philosophy and Pedagogy, Tesis Doctoral. Conservatorio de Birmingham, 2010.

Daniel, R. (2004). Innovations in piano teaching: A small-group model for the tertiary level. Music Education Research, 6 (1), 23-43. doi: 10.1080/1461380032000182911.

Del'son, V. (1966). Genrich Nejgauz. Moscú: Muzyka.

Fomina, N. A. (2010). Kogda stroku diktuet čuvstvo... [Cuando el sentimiento dicta la palabra...]. Kazan': Ministerstvo kul'tury Rossijskoj Federacii. Kazanskaja Gos. Konservatorija im. N. G. Žiganova.

Gaunt, H. (2008). One-to-one tuition in a conservatoire: the perceptions of instrumental and vocal teachers. Psychology of Music, 36, 215-245. doi: 10.1177/0305735607080827.

Gonzol, D. (2004). Otto Rudolph Ortmann Music Philosophy, and Music Education. Philosophy of Music Education Review, 12(2), 160-180. doi: 10.1353/pme.2005.0006

Gornostaeva, V. V. (2007a). Priznanie v ljubvi [Declaración de amor]. En R. A. Caturov (Coord.), Lev Naumov. Sbornik statej i vospominanij (pp. 186-190). Moscú: Deka-VS.

Gornostaeva, V. V. (2007b). O moem učitele [Sobre mi maestro]. En E. Richter (Comp.) Vspominaja Nejgauza (pp. 193-199). Moscú: Izdatel'skij dom “Klassika-XXI".

Hallam, S. (1998). Instrumental teaching. A practical guide to better teaching and learning. Oxford: Heinemann Educational.

Huerta, R. (2010). Investigación por estudios de caso en el aula de música. Actas del I Congreso Internacional de Investigación en Música (Valencia, 25-26 de febrero de 2010), Valencia: Instituto Superior de Enseñanzas Artísticas, Generalitat Valenciana, pp. 18-26.

Kremenštejn, B. L. (1984). Pedagogika G. G. Nejgauza [La Pedagogía de Neuhaus]. Moscú: Muzyka.

Kremenštejn, B. L. (2007). Uroki Nejgauza [Clases de Neuhaus]. En A. V. Malinovskaja (Comp.), Genrich Nejgauz i ego učeniki. Pianisty-gnesincy rasskazyvajut (pp. 9-33). Moscú: Izdatel'skij dom «Klassika-XXI».

Kurkul, W. (2007). Nonverbal communication in one-to-one music performance instruction. Psychology of Music, 35 (2), 327-362. doi: 10.1177/0305735607070385.

Levasseur, S. J. (1994). Nonverbal communication in the applied voice studio. (Disertación Doctoral, Columbia University). Dissertation Abstracts International, 55-07, 1864.

Marčenko, I. P. (1999), Pedagogičeskoe nasledie G. G. Nejgauza v professional'noj podgotovke učitelja muzyki, Dissertacija na soiskanie stepeni kandidata pedagogičeskij nauk. Ural'skij gosudarstvenyj pedagogičeskij universitet, Ekaterimburgo.

Márquez Sánchez, S. (2011). El legado pedagógico, intelectual y estético-musical de un gran maestro: Genrich Gustavovič Nejgauz (1888-1964). Tesis Doctoral. Universidad de Málaga.

Martínez, A., \& Musitu, G. (1995). El estudio de casos para profesionales de la acción social. Madrid: Narcea.

Mathers, A. (2009). The use of gestural modes to enhance expressive conducting at all levels of entering behavior through the use of illustrators, affect displays and regulators. International Journal of Music Education, 27(2), 143-153. doi: $10.1177 / 0255761409102322$.

Neuhaus, H. (1933/2008). Ob opyte obmena opytom [Sobre la experiencia de compartir ex- 
periencias]. En A. F. Chitruk, G. G. Nejgauz. Razmyšlenija. Avtobiografičeskie zametki. Dnevniki. Izbrannye stat'i, (pp. 181-184). Moscú: Deka-VS.

Neuhaus, H. (1937/2008). Dvenadcataja sonata Betchovena. O soderžanii i forme fortepianich sonat Betchovena) [Duodécima sonata de Beethoven. Sobre el contenido y forma de las sonatas para piano de Beethoven)]. En A. F. Chitruk (Comp.), G. G. Nejgauz. Doklady $i$ vystuplenija. Besedy i seminary. Otrkytye uroki. Vospominanija o G. G. Nejgauze (pp. 203-209). Moscú: Deka-VS.

Neuhaus, H. (1938/2007). Work on Beethoven's Sontata in A Major Opus 101. En C. Barnes The Russian Piano School. Russian Pianists \& Moscow Conservatoire Professors on the Art of the Piano (pp. 110-128). London: Kahn \& Averill.

Neuhaus, H. (1938/2008). Dvadcat'vos'maja sonata Betchovena [Sonata número veintiocho de Beethoven]. En A. F. Chitruk (Comp.), G. G. Nejgauz. Doklady i vystuplenija. Besedy i seminary. Otrkytye uroki. Vospominanija o G. G. Nejgauze (pp. 221-240). Moscú: Deka-VS.

Neuhaus, H. (1952, marzo 24/2008). Igrat' ne menše četyrech časov v den' [Tocar no menos de cuatro horas al día]. Sovetskij Muzykant. En Chitruk, A. F. (Comp.) G. G. Nejgauz. Razmyšlenija. Avtobiografičeskie zametki. Dnevniki. Izbrannye stat'i (pp. 304-306). Moscú: Deka-VS.

Neuhaus, H. (1958). Ob iskusstve fortepiannoj igry [El arte del piano]. Moscú: Gosudarstvennoe Muzykal'noe Izdatel'stvo.

Neuhaus, H. (1958/1987). El arte del piano. consideraciones de un profesor (G. González, C. Martín Colinet Trad.). Madrid: Real Musical.

Neuhaus, H. (1960). Vydajušžijsja pianist sovremennosti [Gran pianista de nuestro tiempo], Ogonek, 48. En Chitruk, A. F. (Comp.) G. G. Nejgauz. Razmyšlenija. Avtobiografičeskie zametki. Dnevniki. Izbrannye stat'i (pp. 373-377). Moscú: Deka-VS.

Neuhaus, H. (1962, septiembre 15/2008). Opjat' Mocart i Sal'eri [De nuevo Mozart y Salieri]. Izvestija. En Chitruk, A. F. (Comp.) G. G. Nejgauz. Razmyšlenija. Avtobiografičeskie zametki. Dnevniki. Izbrannye stat'i (pp. 420-430). Moscú: Deka-VS.

Perl'man, N. E. (1992/2008). Iz kievskich vospominanij [Recuerdos de Kiev], Muzykal'naja Akademija, 1. En A. F. Chitruk (Comp.), G. G. Nejgauz. Doklady i vystuplenija. Besedy i seminary. Otrkytye uroki. Vospominanija o G. G. Nejgauze (pp. 261-263). Moscú: Deka-VS.

Richter, E. R. (Comp.) (2007) Vspominaja Nejgauza [Recordando a Neuhaus]. Moscú: Izdatel'skij dom "Klassika-XXI".

Romero Rubio, A. (1996). Información y comunicación educativas: Anteproyecto de código deontológico. CIC: Cuadernos de Información y Comunicación, 2, 159-166.

Rostvall, A. \& West, T. (2003, abril) Teacher-student communication during instrumental lessons, Ponencia presentada en la SEMPRE Conference, Londres, Reino Unido.

Schippers, H. (2006). "As if a little bird is sitting on your finger...": Metaphor as a key instrument in training professional musicians. International Journal of Music Education, 24(3), 209-217. doi: 10.1177/0255761406069640.

Vedernikov, A. I. (2000). O godach moego tvorčeskogo stanovlenija, vstrečach s vydajušžimisja muzykantami, problemach ispolnenija starinnoj i sovremennoj muzyki, voprosach pedagogiki [Sobre los años de mi formación artística, el encuentro con grandes músicos, problemas sobre la interpretación de la música antigua y contemporánea, y cuestiones sobre pedagogía]. En A. M. Merkulov (Comp.). Professora ispolnitel'skij klassov Moskovskoj konservatorii, I, (154-172). Moscú: Moskovskaja gos. Konservatorija im. P. I. Čajkovskogo. 
Voskobojnikov, V. (2008). O samom ljubimom i dorogom. O samych ljubimych i dorogic [Sobre el más amado y querido]. En A. F. Chitruk (Comp.), G. G. Nejgauz. Doklady $i$ vystuplenija. Besedy i seminary. Otrkytye uroki. Vospominanija o G. G. Nejgauze (pp. 347-420). Moscú: Deka-VS.

Woody, R. (2006). Musicians' cognitive processing of imagery-based instructions for expressive performance. Journal of Research in Music Education, 54(2), 125-137. doi: $10.1177 / 002242940605400204$.

Zhukov, K. (2004). Teaching styles and student behaviour in instrumental music lessons in Australian conservatoriums. Tesis Doctoral. University of New South Wales.

Zhukov, K. (2007). Student learning styles in advanced instrumental music lessons. Music Education Research, 9(1), 111-127. doi: 10.1080/14613800601127585.

\subsection{Grabaciones audiovisuales}

Chitruk, A. F. (2008). «Uroki G. G. Nejgauz. Nejgauz zapisany P. V. Lobanovym v 19541962 [Clases de Neuhaus. Grabaciones realizadas por P. V. Lobanov en 1954-1962]» [DVD], en Chitruk, A. F, G. G. Nejgauz. Doklady i vystuplenija. Besedy I seminary. Otrkytye uroki. Vospominanija o G. G. Nejgauze. Moscú: Deka-VS.

Lobanov, V. [ChatlaninUef]. (2009, marzo, 9). Heinrich Neuhaus - A lecture on Symphonic Etudes (part 3). [Archivo de video]. Recuperado de https://www.youtube.com/watch?v=jdfMzKxY0qs

Lobanov, V. [ChatlaninUef]. (2008, marzo, 17). Heinrich Neuhaus - Lecture on Chopin's $4^{\text {th }}$ Ballade. [Archivo de video]. Recuperado de https://www.youtube.com/watch?v=3xmUuWPelk4

Lobanov, V. [ChatlaninUef]. (2008, marzo, 17). Heinrich Neuhaus - Lecture on Chopin's $4^{\text {th }}$ Ballade (part 3). [Archivo de video]. Recuperado de https://www.youtube.com/watch?$\mathrm{v}=\mathrm{vV} \_$vqdxnFQs

Stroeva, V. [CentralMusicSchool]. (2010. Julio, 14). Young Musicians [Archivo de video]. Recuperado de https://www.youtube.com/watch?v=amwgMU4PWVY

Tichonov, N. [Theartsmedia]. (2017, febrero, 16). Master Heinrich. [Archivo de video]. Recuperado de https://www.youtube.com/watch?v=ukIL2Bf0bEM 